\title{
Forecast of China Population under Different Fertility Policy
}

\author{
Jun'e Liu, Lei Chai, Zina Xu \\ The School of Information, Beijing Wuzi University, Beijing, China \\ Email: 884507392@qq.com
}

Received 14 June 2016; accepted 24 July 2016; published 27 July 2016

Copyright (C) 2016 by authors and Scientific Research Publishing Inc.

This work is licensed under the Creative Commons Attribution International License (CC BY). http://creativecommons.org/licenses/by/4.0/

c) (i) Open Access

\begin{abstract}
In this paper, we use queue elements prediction and forecasting software PADIS-INT, set three different fertility programs, and predict China's total population and the trends of population structural change in 2015-2050, based on the fifth and sixth national census data. The results show that since implementation of the two-child family planning policy, the aging trend of the population structure will be significantly improved, and after 2030 our population structure will be gradually younger. In view of the problem of population sex ratio imbalance, we verified it, and the results showed that by 2020 there will be a bachelor phenomenon, but the number did not report as much. Finally, we gave a brief summary and recommendations for our studies.
\end{abstract}

\section{Keywords}

Queue Elements Prediction, PADIS-INT, Population Prediction

\section{Introduction}

Our country has a large global population. The population problem is one of the key issues of socio-economic development, and an important basis for future economic development is to be accurate population structure prediction.

China in 2000 and 2010 respectively conducted the fifth and sixth national census, and $1 \%$ of the national population survey in 2015. This article uses queue elements prediction model and census data of 2000 and 2010, estimates quantitatively the trends of our population change from 2015 to 2050, and discusses relevant demographic change. We find that aging population situation is serious. Our government opened the "single second child" policy in 2013, and implementation of "comprehensive second child" policy in 2015, so this article also discusses the demographic changes after the implementation of appropriate policies. The prediction results showed that the adjustment of fertility policy can improve the birth rate of China's population, reduce the degree 
of aging, increase labor force population and so on. So whether it is the understanding of the economic status quo, or to grasp the development trend of the future, accurate predictions of population and demographic changes are critical.

At the same time, many reports and experts have pointed out that our country has a problem of sex-ratio imbalance. There are media reports that "There will be 3000 to 4000 million bachelors by 2020 ". In this paper, we through a series of analysis and calculation, verified our country's sex ratio imbalance problem, and gave some suggestions.

\section{Forecasting Methods and Software}

There are many models and ways to carry out population forecast, such as: linear regression model, the amount of average growth, exponential smoothing, gray system GM, the age-shifting algorithm, matrix equations and the like. This paper uses a queue element prediction method, which is based on population itself change the elements and sub-elements of prediction methods demographic principles, not only can predict the size of the population, but also can predict the population structure, population prediction of the most widely used method.

\subsection{Queue Element Prediction Method}

The population of any area, there is always births, deaths, migration and other phenomena, in constant development of variation, but the basic theory of demographic changes in the population and a large number of facts show that when the population of a region to achieve a larger scale, their different gender, age group of the population over time generally have relatively stable characteristics. Carried out according to population projections queue element method the basic principles and ideas, is to use this feature, for each age group population prediction area, set its rate of change in a future period, are calculated accordingly within a future period the number of deaths and net migration, with its population at the beginning of the addition and subtraction, to arrive at the end of the forecast population to a higher age group.

Now 5 years old by age group from the packet, the time interval at 5-year forecast, we build model:

$$
\begin{array}{ll}
M_{x, t+5}=\left(p_{x, t}^{m}+m_{x, t}^{m}\right) \cdot M_{x-s, t} & 5 \leq x \leq 95 \\
F_{x, t+5}=\left(p_{x, t}^{f}+m_{x, t}^{f}\right) \cdot F_{x-5, t} & 5 \leq x \leq 95 \\
B_{t}=\sum_{x=15}^{49}\left(\left(F_{x, t}+F_{x, t+5}\right) \cdot b_{x, t} \cdot \frac{5}{2}\right) & \\
B_{t, m}=B_{t} \cdot \frac{r}{100+r} & \\
B_{t, f}=B_{t}-B_{t, m} \\
M_{0, t+5}=\left(p_{0, t}^{m}+m_{0, t}^{m}\right) \cdot B_{t, m} \\
F_{0, t+5}=\left(p_{0, t}^{f}+m_{0, t}^{m}\right) \cdot B_{t, f} \\
M_{95, t+5}=\left(p_{95, t}^{m}+m_{95, t}^{m}\right) \cdot\left(M_{90, t}+M_{95, t}\right) \\
F_{95, t+5}=\left(p_{95, t}^{f}+m_{95, t}^{f}\right) \cdot\left(F_{90, t}+F_{95, t}\right)
\end{array}
$$

On behalf of the meaning of each symbol of the formula which follows as Table 1.

\subsection{Prediction Software PADIS-INT}

PADIS-INT is under the guidance of the United Nations Population Division, the China Population and Development Research Center population projections developed by international software, which has seven advantages: 1) powerful, it can combine long-term with short-term forecasting, so we can assess pushed back 100 years and predict the future in 400 years, it also can formulate high, medium and low three kinds of programs, simul- 
Table 1. Related symbol description.

\begin{tabular}{|c|c|c|c|}
\hline Symbolic variable & Variable means & Symbolic variable & Variable means \\
\hline$M_{x, t}$ & $\begin{array}{l}\text { male population in } \\
\text { the } x \sim x+4 \text { age group } \\
\qquad(x=0,5,10, \cdots, 95)\end{array}$ & $P_{0, t}^{m}$ & $\begin{array}{l}\text { probability of survival that male } \\
\text { infants born in the years } t \sim t+5 \text { became } \\
0 \sim 4 \text { age group population to } t+5 \text { year }\end{array}$ \\
\hline$F_{x, t}$ & $\begin{array}{l}\text { female population in } \\
\text { the } x \sim x+4 \text { age group } \\
\qquad(x=0,5,10, \cdots, 95)\end{array}$ & $P_{0, t}^{f}$ & $\begin{array}{l}\text { probability of survival that female } \\
\text { infants born in the years } t \sim t+5 \text { became } \\
0-4 \text { age group populationto } t+5 \text {-year }\end{array}$ \\
\hline$M_{100, t}$ & $\begin{array}{l}\text { Men Elderly Population } \\
\text { over } 100 \text { years old }\end{array}$ & $b_{x, t}$ & $\begin{array}{c}\text { female population fertility of } \\
x \sim x+4 \text { age group in the year } t \sim t+5\end{array}$ \\
\hline$F_{100, t}$ & $\begin{array}{l}\text { Women Elderly Population } \\
\text { over } 100 \text { years old }\end{array}$ & $m_{x, t}^{m}$ & $\begin{array}{l}\text { net migration rate of the male population } \\
\text { in } x-5 \sim x-1 \text { years old age group in } t \text { year } \\
\text { to } t+5 \text { years } x \sim x+4 \text { age group of } \\
\text { the population during the forecast period }\end{array}$ \\
\hline$B_{t}$ & $\begin{array}{l}t \sim t+5 \text { years, the } \\
\text { number of babies born }\end{array}$ & $m_{x, t}^{f}$ & $\begin{array}{l}\text { net migration rate of the female population } \\
\text { in } x-5 \sim x-1 \text { years old age group in } t \text { year } \\
\text { to } t+5 \text { years } x \sim x+4 \text { age group of } \\
\text { the population during the forecast period }\end{array}$ \\
\hline$B_{t, m}$ & $\begin{array}{l}\text { number of male infants } \\
\text { born between } t \sim t+5\end{array}$ & $m_{0, t}^{m}$ & $\begin{array}{l}\text { net migration rate of male infants } \\
\text { born in } t \sim t+5 \text { year become a } \\
\text { population of } 0-4 \text { year-old age } \\
\text { group to } t+5 \text { years }\end{array}$ \\
\hline$B_{t, f}$ & $\begin{array}{l}\text { number of female infants } \\
\text { born between } t \sim t+5\end{array}$ & $m_{0, t}^{f}$ & $\begin{array}{l}\text { net migration rate of female infants } \\
\text { born in } t \sim t+5 \text { year become a } \\
\text { population of } 0 \text { - } 4 \text { year-old age } \\
\text { group to } t+5 \text { years }\end{array}$ \\
\hline$r$ & sex ratio at birth & $m_{95, t}^{m}$ & $\begin{array}{l}\text { net migration rate of the male } \\
\text { population over the age of } 90 \\
\text { in } t \text { year become male over the } \\
\text { age of } 95 \text { group in } t+5 \text { year }\end{array}$ \\
\hline$P_{x, t}^{m}$ & $\begin{array}{l}\text { survival probability of male } \\
\text { population in } x-5 \sim x-1 \text { years } \\
\text { old age group in } t \text { year to } t+5 \\
\text { year in } x \sim x+4 \text { age group }\end{array}$ & $m_{95, t}^{f}$ & $\begin{array}{l}\text { net migration rate of the female } \\
\text { population over the age of } 90 \\
\text { in } t \text { year become male over the } \\
\text { age of } 95 \text { group in } t+5 \text { year }\end{array}$ \\
\hline$P_{x, t}^{f}$ & $\begin{array}{l}\text { survival probability of female } \\
\text { population in } x-5 \sim x-1 \text { years } \\
\text { old age group in } t \text { year to } t+5 \\
\text { year in } x \sim x+4 \text { age group }\end{array}$ & & \\
\hline
\end{tabular}

taneously in eight countries (or regional, ethnic) forecast. There is no precedent in the international arena; 2) High accuracy, with the United Nations predicted population as the reference, the error rate of the main result is less than 1\%; 3) Convenient, web-based, any browser, anywhere in the world it can be used in real time; 4) Visual effects, and a variety of graphics display, clearly visible contrast; 5) It reflects the international direction, using the six working languages of the United Nations, to facilitate global promotion; 6) Enter simple, rich output, effective decision-making to support economic and social development; 7) Advanced technology, combine the population forecast technology with the modern information technology. 
Use PADIS-INT forecast software needs to set the following parameters:

1) The amount of people by sex and age in the base year.

2) Mortality levels during the forecast period.

3) Select the model life table.

4) Fertility levels during the forecast period-the total fertility rate.

5) Fertility patterns, the fertility level of women of childbearing age.

6) Sex ratio at birth during the forecast period.

7) Migration levels during the forecast period.

8) Migration patterns.

\section{Empirical Analysis}

Based on the date of the sixth census, we designed fertility policy remains unchanged, "two children alone" policy, "a comprehensive two children" policy implementation of the three programs, and predicted China's population trends from 2015 to 2050 respectively, and by comparing the results of the analysis to predict the impact on China to curb the population growth.

\subsection{Model Assumptions}

1) When forecasting the total population, we assumed that net immigration rate is 0 .

2) When setting up three different levels of fertility, it is assumed: the scenario where the fertility level in 2020 reached 1.8, and thereafter will stabilize at 1.8 unchanged; high levels of fertility programs in 2016 reached the highest point of 1.94, 2020 decreased to 1.8, then it will remain at this level.

3) Male life assumed an increase of 2.7 years per decade when setting the level of mortality, female life expectancy rose by 3.4 years per decade.

4) Suppose after 15 years to achieve normal levels when setting sex ratio at birth, which varies linearly 2025 to maintain the level of 107, then it will remain at this level from 2026 to 2050.

\subsection{Data in the Base Period}

Data base period is the starting point for the calculation model, select the exact data base of the model to predict the accuracy of the results have a significant impact. This paper selects 2010, China's sixth population census data and checks the data as part of the data base, the total population every 5 years for a group of $0-79$ years old population will be divided into 16 groups, the population aged 80 and over return as a group.

\subsection{Prediction and Parameter Settings}

Mainly refers to the prediction of fertility, mortality, sex ratio, net immigration rate. Parameters to predict based on the sixth census in 2010, and make reasonable adjustments, in order to predict the future and structure of the total number of population trends.

\subsubsection{Fertility Rate}

Fertility rate is an important variable in the formation of the new population, and one of factors that bring about the population increase. Prediction and set our total fertility rate is mainly based on the qualitative analysis of family planning policy. According to the 2010 census data show that the national total fertility rate of 1.18 , the results of calculations of experts is only 1.5 - 1.6, far below the population replacement level. Affected "two children alone" and "full two children" Policy, many scholars have pointed out in the short term may be a slight rebound in the fertility rate, but in the long run will not be ups and downs. Zhai Zhenwu said at the seminar "single second child" policy will make our total fertility rate have a relatively significant rise, the highest point may be more than 1.8 (but not more than two), but the cumulative effect of the release of fertility will fluctuations in 1.6 - 1.7. "National Population Development Strategy Research Report" (2006) pointed that if the total population peak at 15 million people around the country in the next 30 years, the total fertility rate should be maintained at about 1.8, too high or too low is not conducive to population and coordinated economic and social development [1].

Therefore, this article on the set forecast fertility levels assumed three programs: 
Option One (low program): Constant fertility, fertility and fertility of the sixth census data is the same throughout the period, as shown in Table 2.

Option II (middle program): Fertility levels gradually increased from 2014 to 2020 to reach 1.8 thereafter will stabilize at 1.8 unchanged, as shown in Table 3.

Option III (high program): Next few years, the total fertility rate increased in 2016 to reach the highest point of 1.94, and then began to decline in 2020 dropped to 1.8, then it will remain at this level, as shown in Table 4.

\subsubsection{Death Level}

Death level is related of the expected life. From the point of view of China's total population, over the past few decades the average growth of 2.77 years per decade for Men, Women average increase of 3.45 years per decade. Because of medical conditions and people's living standards have greatly enhanced than before, it is expected that the life will continue to grow for some time. In general, the higher the average life expectancy, the slower speed. Therefore, we assume that male life expectancy grew 2.7 years per decade, female life expectancy rose by 3.4 years per decade. Male and female life expectancy from 2010 to 2050 as shown in Table 5 .

\subsubsection{Death Mode}

Using the software PADIS-INT conducted population projections, the impact of death is determined by the project setting mode of the selected model life tables, the software provides two categories of life table: Kou de Man and the United Nations life table.

The West model of Kou Halderman life table model established on the basis of 130 real life table data, and these life table mainly from Africa and Asia, such as Israel, Japan and Taiwan Province of China and South Africa. Their mortality data had no significant systematic bias, so this set of models than other groups more broadly representative, be regarded as the standard model life table. Therefore, this study choose Kou Halderman West model life table to predict the development trend of China's population.

\subsubsection{Sex Ratio at Birth}

In the absence of interference of human factors, the sex ratio at birth should be relatively stable, ranging between 103 - 107, in different countries, nations differ slightly from the normal of about 107 often, if a serious deviation from this range, It will cause a series of social problems [2].

According to the sixth national census data, in 2010 China's sex ratio at birth was 104.90.Former director of the National Population and Family Planning Commission Zhang Weiqing pointed out, 10 to 15 years and strive to achieve normal sex ratio at birth. Therefore, based on the current sex ratio at birth of 104.90, we assumptted that after 15 years to achieve a normal level, which varies linearly 2025 to maintain the level of 107, then constant 107 from 2026 to 2050, as shown in Table 6.

\subsubsection{Migration Levels}

China, as a whole, the geographical scope of internal migration will not have any impact on the number of

Table 2. Low program: 2010 women of childbearing age groups fertility.

\begin{tabular}{cccccccccc}
\hline Age group (y) & $15-19$ & $20-24$ & $25-29$ & $30-34$ & $35-39$ & $40-44$ & $45-49$ & Total fertility rate \\
\hline Fertility rate (\%) & 5.93 & 69.47 & 84.08 & 45.84 & 18.71 & 7.51 & 4.68 & 1181 \\
\hline
\end{tabular}

Table 3. Middle program: The total fertility rate for each year 2011-2050.

\begin{tabular}{rrrrrrrrrrrrrrr}
\hline Year & 2011 & 2012 & 2013 & 2014 & 2015 & 2016 & 2017 & 2018 & 2019 & 2020 & $\ldots$ & 2050 \\
\hline TFR & 1.242 & 1.304 & 1.366 & 1.428 & 1.49 & 1.552 & 1.614 & 1.676 & 1.738 & 1.8 & 1.8 & 1.8 \\
\hline
\end{tabular}

Table 4. High program: The total fertility rate for each year 2011-2050.

\begin{tabular}{rrrrrrrrrrrrrrr} 
Year & 2011 & 2012 & 2013 & 2014 & 2015 & 2016 & 2017 & 2018 & 2019 & 2020 & $\ldots$ & 2050 \\
\hline TFR & 1.18 & 1.18 & 1.18 & 1.18 & 1.56 & 1.94 & 1.905 & 1.87 & 1.835 & 1.8 & 1.8 & 1.8 \\
\hline
\end{tabular}


Table 5. Life expectancy of women and men 2010-2050.

\begin{tabular}{|c|c|c|c|c|c|}
\hline Year & Man & Women & Year & Man & Women \\
\hline 2000 & 69.63 & 73.33 & 2031 & 78.05 & 84.51 \\
\hline 2010 & 72.38 & 77.37 & 2032 & 78.32 & 84.85 \\
\hline 2011 & 72.65 & 77.71 & 2033 & 78.59 & 85.19 \\
\hline 2012 & 72.92 & 78.05 & 2034 & 78.86 & 85.53 \\
\hline 2013 & 73.19 & 78.39 & 2035 & 79.13 & 85.87 \\
\hline 2014 & 73.46 & 78.73 & 2036 & 79.4 & 86.21 \\
\hline 2015 & 73.73 & 79.07 & 2037 & 79.67 & 86.55 \\
\hline 2016 & 74.00 & 79.41 & 2038 & 79.94 & 86.89 \\
\hline 2017 & 74.27 & 79.75 & 2039 & 80.21 & 87.23 \\
\hline 2018 & 74.54 & 80.09 & 2040 & 80.48 & 87.57 \\
\hline 2019 & 74.81 & 80.43 & 2041 & 80.75 & 87.91 \\
\hline 2020 & 75.08 & 80.77 & 2042 & 81.02 & 88.25 \\
\hline 2021 & 75.35 & 81.11 & 2043 & 81.29 & 88.59 \\
\hline 2022 & 75.62 & 81.45 & 2044 & 81.56 & 88.93 \\
\hline 2023 & 75.89 & 81.79 & 2045 & 81.83 & 89.27 \\
\hline 2024 & 76.16 & 82.13 & 2046 & 82.1 & 89.61 \\
\hline 2025 & 76.43 & 82.47 & 2047 & 82.37 & 89.95 \\
\hline 2026 & 76.7 & 82.81 & 2048 & 82.64 & 90.29 \\
\hline 2027 & 76.97 & 83.15 & 2049 & 82.91 & 90.63 \\
\hline 2028 & 77.24 & 83.49 & 2050 & 83.18 & 90.97 \\
\hline 2029 & 77.51 & 83.83 & & & \\
\hline 2030 & 77.78 & 84.17 & & & \\
\hline
\end{tabular}

population change (which is, without regard to internal migration between regions), and low net migration rate of population between China and overseas, and migration factors influence population changes negligible [3]. Therefore, this article does not consider the transfer of population, population migration assumed to be zero.

\section{Result Analysis}

According to demographic data and relevant parameters of the above assumption, we run software PADIS-INT, obtained predictions of population size and structure under three scenarios of each year by age and sex, the results are as follows.

\subsection{Analysis of the Total Population}

\subsubsection{Total Population}

Number of programs at three of China's total population in 2011-2050 as shown in Table 7; Total population trend analysis and the results of comparison shown in Figure 1.

Based on the above chart analysis, we can see:

1) Fertility Policy adjustment brought about the increase of total population, the overall trend showed a decrease after an initial increase. Forecast results show that if implement "comprehensive second child" policy, China's total population in 2020 will from 1.36 billion people increase to 1.4 billion people, and reach a peak 
Table 6. 2011-2050 the sex ratio at birth.

\begin{tabular}{|c|c|c|c|}
\hline Year & Sex ratio at birth & Year & Sex ratio at birth \\
\hline 2011 & 105.04 & 2031 & 107 \\
\hline 2012 & 105.18 & 2032 & 107 \\
\hline 2013 & 105.32 & 2033 & 107 \\
\hline 2014 & 105.46 & 2034 & 107 \\
\hline 2015 & 105.6 & 2035 & 107 \\
\hline 2016 & 105.74 & 2036 & 107 \\
\hline 2017 & 105.88 & 2037 & 107 \\
\hline 2018 & 106.02 & 2038 & 107 \\
\hline 2019 & 106.16 & 2039 & 107 \\
\hline 2020 & 106.3 & 2040 & 107 \\
\hline 2021 & 106.44 & 2041 & 107 \\
\hline 2022 & 106.58 & 2042 & 107 \\
\hline 2023 & 106.72 & 2043 & 107 \\
\hline 2024 & 106.86 & 2044 & 107 \\
\hline 2025 & 107 & 2045 & 107 \\
\hline 2026 & 107 & 2046 & 107 \\
\hline 2027 & 107 & 2047 & 107 \\
\hline 2028 & 107 & 2048 & 107 \\
\hline 2029 & 107 & 2049 & 107 \\
\hline 2030 & 107 & 2050 & 107 \\
\hline
\end{tabular}

1.439 billion people in 2044, after a downward trend, by 2050 the total population approximately is14.34 billion.

2) The total population reached a peak in 2044, compared with Cai Fang, editor of “China's Sustainable Development Master Plan (national volume)—China Population and Sustainable Development” in the projections of the total population peak will occur in 2033, delayed nearly 10 years. The reason is because the implementation of "comprehensive second child" policy, so that the total fertility rate fluctuate slightly in the short term, in 2016 reached the highest point of 1.94, bringing the total population peak was delayed, but the total population is still showing the trend of at first increased then decreased after, and did not show significant growth.

\subsubsection{Birth}

Number of programs at three of China's birth in 2011-2050 as shown in Table 8; Birth trends analysis and the results of comparison shown in Figure 2.

Based on the above chart analysis, we can see:

1) With the implementation of “Alone two children," our birth once a small peak in 2014-2020 years, after slow growth in the number of population, and the population reached a peak in 2040, about 1434 million people, and the number of birth is about 12,993,397 people by 2050.

2) By comparison between the three programs can be seen to curb the facilities did not bring skyrocketing population, but gradually improve fertility policy, in line with the law of population development, help stabilize moderately low fertility level, slowing total population in the rapid decline after reaching a peak of momentum and in favor of long-term balanced development of population. 
Table 7. China's total population trends.

\begin{tabular}{|c|c|c|c|c|c|c|c|}
\hline Year & Low program & Middle program & High program & Year & Low program & Middle program & High program \\
\hline 2010 & 1332810869 & 1332810869 & 1332810869 & 2031 & 1343293849 & 1432119789 & 1436046090 \\
\hline 2011 & 1336031187 & 1336699699 & 1336031187 & 2032 & 1339718492 & 1432964245 & 1436815419 \\
\hline 2012 & 1339391584 & 1341410798 & 1339391584 & 2033 & 1335872869 & 1433588223 & 1437357337 \\
\hline 2013 & 1342783073 & 1346837172 & 1342783073 & 2034 & 1331760239 & 1434034901 & 1437706741 \\
\hline 2014 & 1346098487 & 1352859082 & 1346098487 & 2035 & 1327381399 & 1434346775 & 1437900419 \\
\hline 2015 & 1349252379 & 1359368629 & 1353374628 & 2036 & 1322735978 & 1434563498 & 1437991353 \\
\hline 2016 & 1352154201 & 1366239256 & 1364395650 & 2037 & 1317822058 & 1434712848 & 1438049846 \\
\hline 2017 & 1354728065 & 1373351466 & 1374551855 & 2038 & 1312630623 & 1434808287 & 1438126171 \\
\hline 2018 & 1356893544 & 1380568746 & 1383743204 & 2039 & 1307157602 & 1434861536 & 1438250132 \\
\hline 2019 & 1358595775 & 1387780255 & 1391909947 & 2040 & 1301398743 & 1434877243 & 1438418894 \\
\hline 2020 & 1359795269 & 1394888858 & 1399015852 & 2041 & 1295357184 & 1434858321 & 1438611595 \\
\hline 2021 & 1360492220 & 1401278264 & 1405404291 & 2042 & 1289029037 & 1434788774 & 1438798572 \\
\hline 2022 & 1360685972 & 1406953051 & 1411078348 & 2043 & 1282402591 & 1434633565 & 1438946500 \\
\hline 2023 & 1360388412 & 1411935770 & 1416060290 & 2044 & 1275466181 & 1434350652 & 1439006553 \\
\hline 2024 & 1359617112 & 1416257585 & 1420381266 & 2045 & 1268212707 & 1433899641 & 1438911406 \\
\hline 2025 & 1358398506 & 1419962468 & 1424085315 & 2046 & 1260636621 & 1433240186 & 1438594670 \\
\hline 2026 & 1356762331 & 1423099506 & 1427221580 & 2047 & 1252732949 & 1432333489 & 1438005560 \\
\hline 2027 & 1354733164 & 1425715335 & 1429832601 & 2048 & 1244513406 & 1431158167 & 1437122655 \\
\hline 2028 & 1352341075 & 1427866757 & 1431969239 & 2049 & 1235984917 & 1429690209 & 1435919842 \\
\hline 2029 & 1349615859 & 1429611557 & 1433680774 & 2050 & 1227151804 & 1427909360 & 1434370797 \\
\hline 2030 & 1346594297 & 1431013628 & 1435018961 & & & & \\
\hline
\end{tabular}

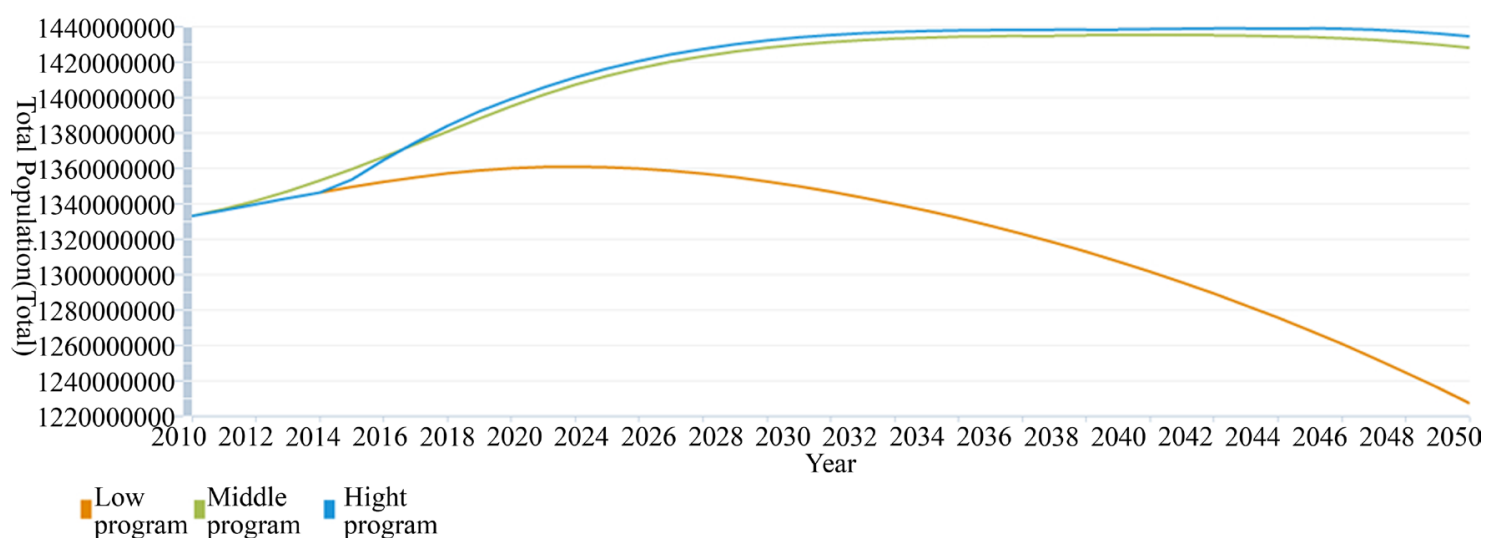

Figure 1. The total number of population trends under three programs.

\subsubsection{Workforce}

Number of programs at three of China’s Workforce in 2011-2050 as shown in Table 9; Workforce trends analysis and the results of comparison shown in Figure 3.

Based on the Table 9 and Figure 3 analysis, we can see: 
Table 8. Birth of the total population trends.

\begin{tabular}{|c|c|c|c|c|c|c|c|}
\hline Year & Low program & Middle program & High program & Year & Low program & Middle program & High program \\
\hline 2011 & 12899084 & 13576888 & 12899084 & 2031 & 8263321 & 12716973 & 12637006 \\
\hline 2012 & 13040006 & 14410383 & 13040006 & 2032 & 8152308 & 12618662 & 12542643 \\
\hline 2013 & 13098761 & 15163560 & 13098761 & 2033 & 8052071 & 12568076 & 12485270 \\
\hline 2014 & 13065109 & 15811081 & 13065109 & 2034 & 7958828 & 12564752 & 12466954 \\
\hline 2015 & 12955961 & 16359727 & 17128220 & 2035 & 7869170 & 12607025 & 12488517 \\
\hline 2016 & 12765612 & 16790097 & 20987531 & 2036 & 7780944 & 12691011 & 12565099 \\
\hline 2017 & 12508140 & 17108642 & 20193226 & 2037 & 7692116 & 12804226 & 12713560 \\
\hline 2018 & 12178747 & 17297977 & 19300218 & 2038 & 7596571 & 12933250 & 12914786 \\
\hline 2019 & 11801747 & 17382577 & 18352716 & 2039 & 7492408 & 13069464 & 13141356 \\
\hline 2020 & 11388673 & 17372541 & 17372552 & 2040 & 7380567 & 13206842 & 13361549 \\
\hline 2021 & 10971124 & 16735593 & 16735614 & 2041 & 7263324 & 13338505 & 13552103 \\
\hline 2022 & 10562161 & 16111743 & 16111771 & 2042 & 7138933 & 13450720 & 13709426 \\
\hline 2023 & 10173398 & 15518705 & 15518742 & 2043 & 7003499 & 13528334 & 13833818 \\
\hline 2024 & 9810810 & 14965603 & 14965643 & 2044 & 6857526 & 13564777 & 13910184 \\
\hline 2025 & 9482074 & 14464147 & 14464181 & 2045 & 6705067 & 13561187 & 13919450 \\
\hline 2026 & 9190628 & 14019580 & 14019602 & 2046 & 6546472 & 13516422 & 13861395 \\
\hline 2027 & 8933754 & 13631921 & 13627760 & 2047 & 6383927 & 13433677 & 13753337 \\
\hline 2028 & 8716842 & 13311285 & 13296877 & 2048 & 6218724 & 13315094 & 13609412 \\
\hline 2029 & 8537370 & 13056439 & 13023107 & 2049 & 6053068 & 13165008 & 13431867 \\
\hline 2030 & 8387509 & 12859015 & 12794504 & 2050 & 5890554 & 12993397 & 13226711 \\
\hline
\end{tabular}

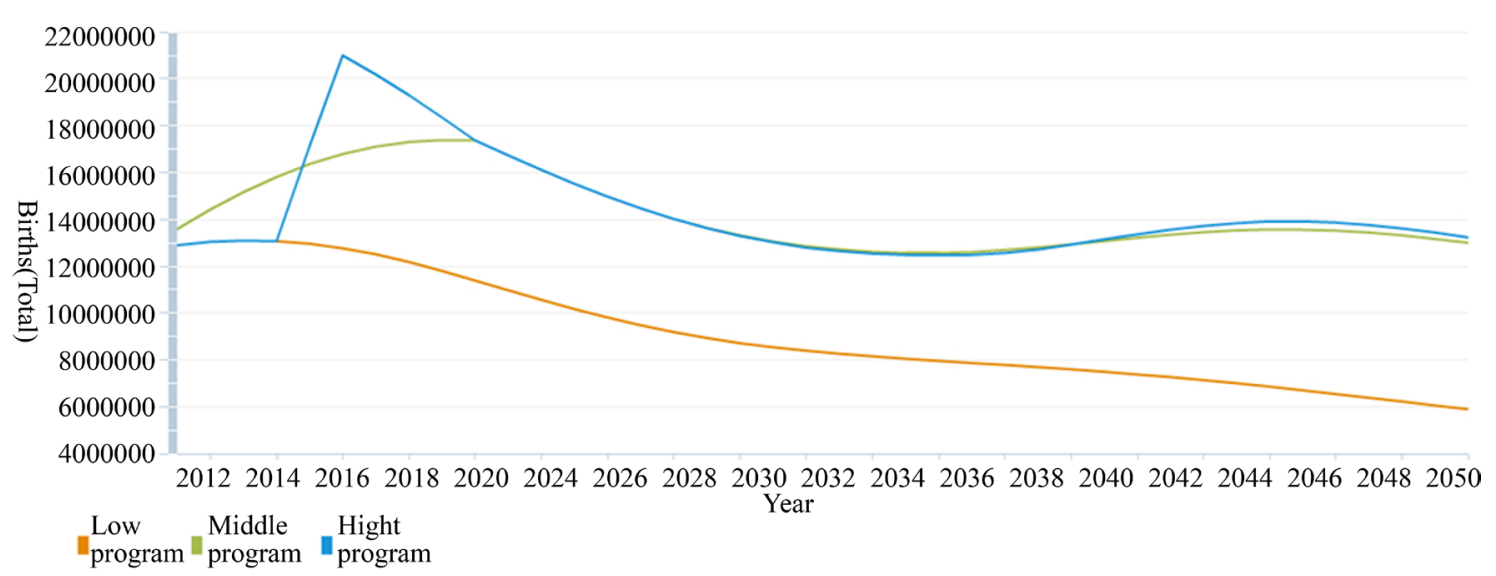

Figure 2. Born population trends under three scenarios.

1) Labor force continued to decline, but the implementation of the new fertility policy enables our country appears to increase the number of labor force in 2030. Under "Comprehensive second child" policy in 2030, China's labor population increased to 819,091,027 from the 814,988,330 people, by the year 2050 increased to $681,412,849$ from the $571,151,238$ people.

"Two children alone” and "full two children" to curb the generally affect only a few labor force after 2) 2030, 
Table 9. Tendency of the total workforce.

\begin{tabular}{|c|c|c|c|c|c|c|c|}
\hline Year & Low program & Middle program & High program & Year & Low program & Middle program & High program \\
\hline 2010 & 933893808 & 933893808 & 933893808 & 2031 & 803324282 & 817362045 & 815516199 \\
\hline 2011 & 933460096 & 933460096 & 933460096 & 2032 & 791707056 & 810271138 & 811463194 \\
\hline 2012 & 931291749 & 931291749 & 931291749 & 2033 & 780059146 & 803662269 & 806827248 \\
\hline 2013 & 927380830 & 927380830 & 927380830 & 2034 & 768941961 & 798040927 & 802162087 \\
\hline 2014 & 923574442 & 923574442 & 923574442 & 2035 & 758281755 & 793275804 & 797396439 \\
\hline 2015 & 919852013 & 919852013 & 919852013 & 2036 & 748916017 & 789590223 & 793710110 \\
\hline 2016 & 917655107 & 917655107 & 917655107 & 2037 & 739903609 & 786047315 & 790166351 \\
\hline 2017 & 915478848 & 915478848 & 915478848 & 2038 & 731233326 & 782646209 & 786764367 \\
\hline 2018 & 913311237 & 913311237 & 913311237 & 2039 & 722074399 & 778569600 & 782686882 \\
\hline 2019 & 910514291 & 910514291 & 910514291 & 2040 & 712457473 & 773865626 & 777982034 \\
\hline 2020 & 907037252 & 907037252 & 907037252 & 2041 & 702333330 & 768504363 & 772619901 \\
\hline 2021 & 902103789 & 902103789 & 902103789 & 2042 & 691816302 & 762622164 & 766732727 \\
\hline 2022 & 896335596 & 896335596 & 896335596 & 2043 & 680944083 & 756283434 & 760378935 \\
\hline 2023 & 889668969 & 889668969 & 889668969 & 2044 & 669006112 & 748805585 & 752867368 \\
\hline 2024 & 882564926 & 882564926 & 882564926 & 2045 & 655989675 & 740203213 & 744200479 \\
\hline 2025 & 874976831 & 874976831 & 874976831 & 2046 & 640057904 & 728668870 & 732586359 \\
\hline 2026 & 863666226 & 864330985 & 863666226 & 2047 & 622914488 & 715936516 & 719778163 \\
\hline 2027 & 851795119 & 853804656 & 851795119 & 2048 & 604516846 & 702000138 & 705759228 \\
\hline 2028 & 839257176 & 843294069 & 839257176 & 2049 & 587281453 & 689316122 & 692977811 \\
\hline 2029 & 827016863 & 833751386 & 827016863 & 2050 & 571151238 & 677869081 & 681412849 \\
\hline 2030 & 814988330 & 825068429 & 819091027 & & & & \\
\hline
\end{tabular}

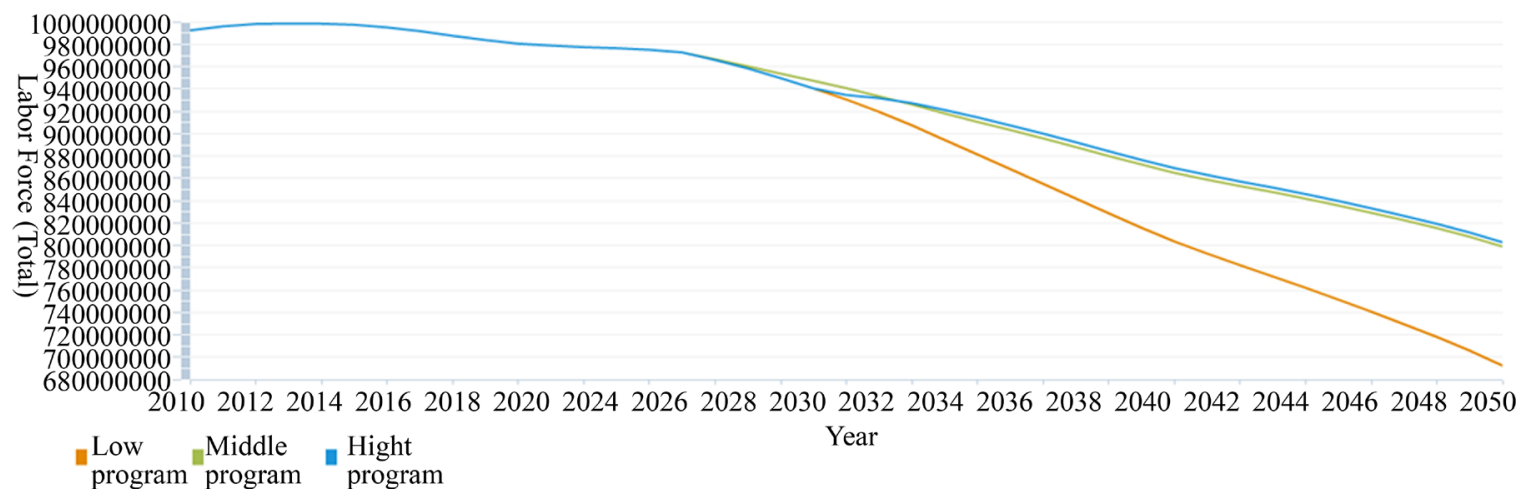

Figure 3. Labor force trends under three programs.

compared with the two solutions, the biggest difference can be seen in the number of working-age population appeared in 2034, workforce from 798,040,927 to 802,162,087 people, more than 4,121,160 people.

In summary it can be seen, the adjustment of Family Planning Policy can increase labor force aged population, 2050 of 15 - 59 year-old working-age population increased from 571,151,238 to 681,412,849. Additional popu- 
lation to some extent complementary labor age population size, slowing the reduction of labor supply phenomenon.

\subsection{Population Structure Analysis}

2010 demographic pyramid and the pyramid structures of three programs shown in Figures 4-8.

By analyzing the graphic of our population pyramid chart in 2010 can be found, the proportion of the population aged 0 - 14 was significantly smaller than the proportion of 15 - 49 years old, population structure began to show a "in" word forms, namely "middle, two small" form. shows the increasingly aging population structure, but also indicates that China’s first demographic dividend coming to an end.

In the low program, from 2020 demographic pyramid graphics can be seen that in 2020 China's population pyramid was "the" shape is more obvious, indicates the number of births further reduce, the trend of population aging be more obvious; from 2050 demographic pyramid graphics can be seen, Population pyramid inverted triangle shape, shows the proportion of new-born population further lower than 2020, and the population structure was severely aging state.

In the middle program, observation of the demographic pyramid in 2020 found that the bottom of the pyramid population aged 0 - 14 to improve the proportion of low birth plan by $14.7 \%$, which is due to changes in fertility. Observed 2050 population pyramid structure found, the proportion of the population aged 60 - 65 is greater than the proportion of other age groups. If we reject this age, look younger population structure, in line with moderate aging demographic characteristics, indicating that changes in fertility rate has gradually improve China's aging population trend.

In the high program, observation of the demographic pyramid discovered in 2020, was at the bottom of the pyramid proportion of the population aged 0 - 14 lower fertility program has been greatly improved, the proportion of the population over 40 years of age is relatively large, 15 - 30 age population proportion of small, showing a "two big middle small" form, which shows changes in fertility brought a large number of new and young people, significantly changed the original trend of demographic changes. Observation of 2050 demographic pyramid found that the proportion of the population aged 60 - 65 is more than any other age group, if this age excluded, demographic look younger, consistent with a mild aging demographic characteristics. This shows that high fertility not only completely changed the structure of the original population aging trend, but to make our country a young population structure and becomes excessive, indicating China's total population will enter another period of rapid growth.

In addition, changes can also be seen from the line chart of the median age of the three programs, it becomes more and more young, as shown in Figure 8.

As can be seen from Figure 8, without changing fertility policy, "two children alone" policy of "full two children," three different programs, China's population structure becomes more and more young. If does not change its policy of growth, the structure of our population median age of over 50 years, will reach 60 years of age, the aging serious, but if change the fertility policy, the median age will be reduced to 50 years of age, changed the structure of the original population aging trend, the population structure has become more younger.

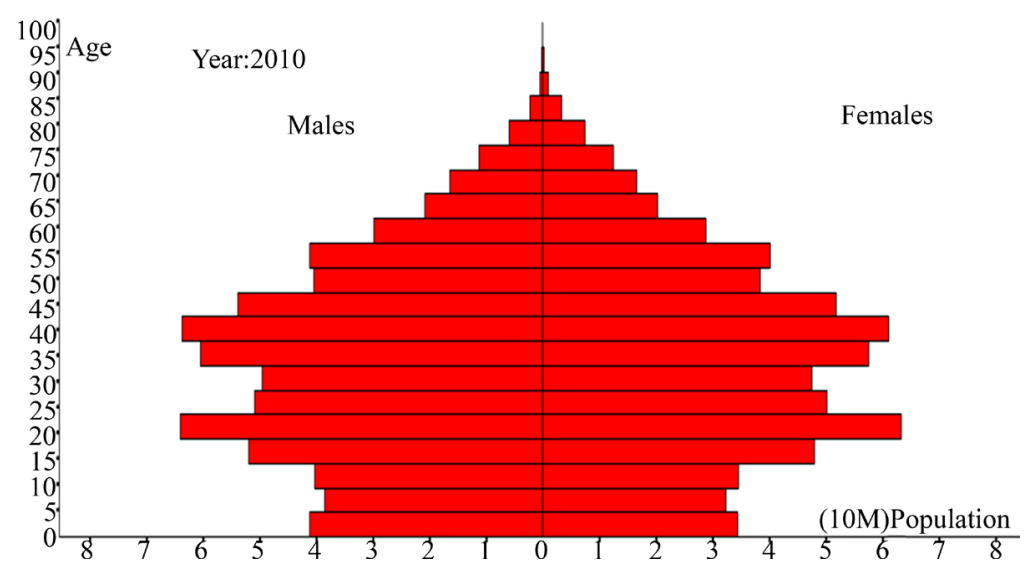

Figure 4. By 2010 the demographic pyramid. 

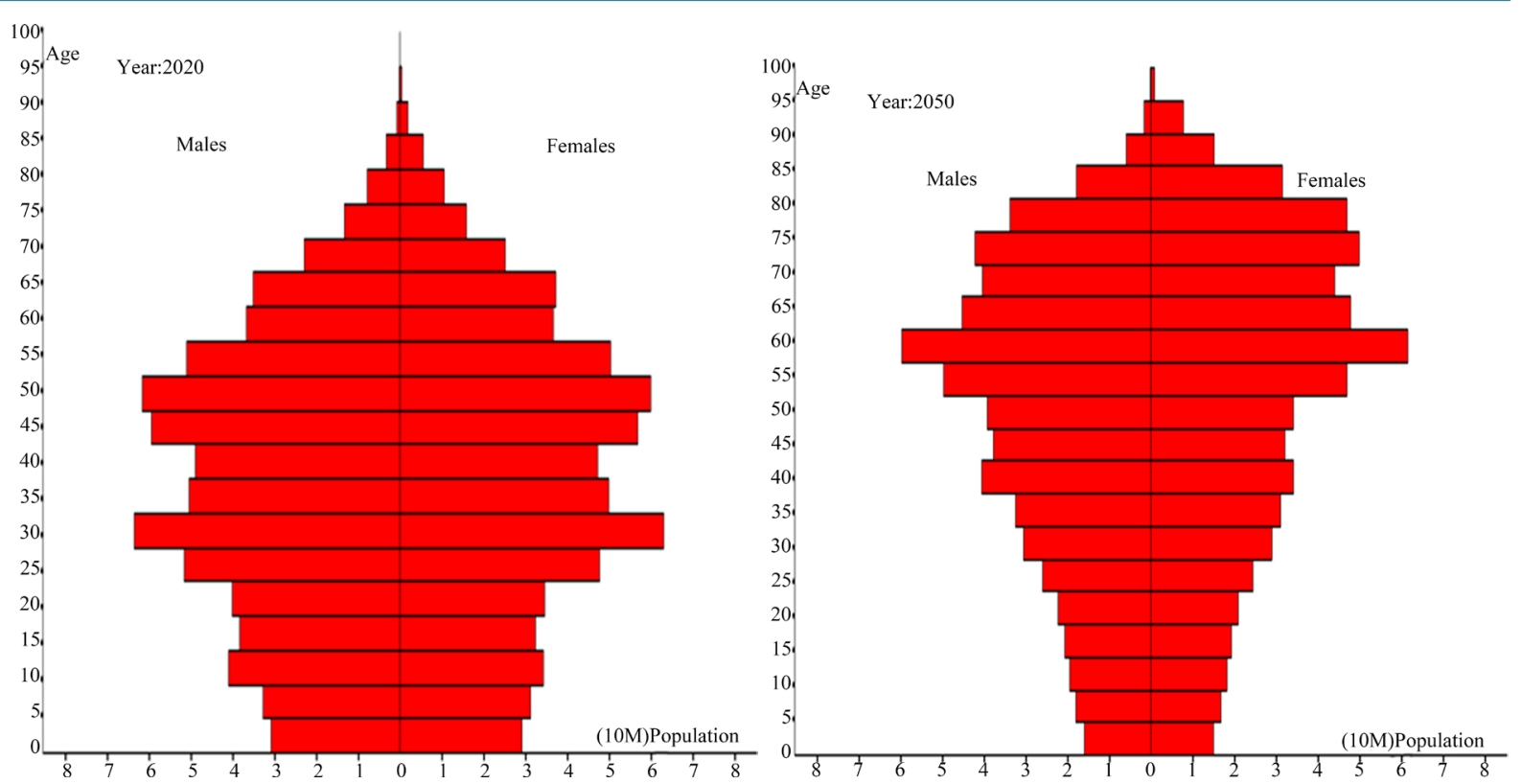

Figure 5. Low program: demographic pyramid in 2020, 2050.
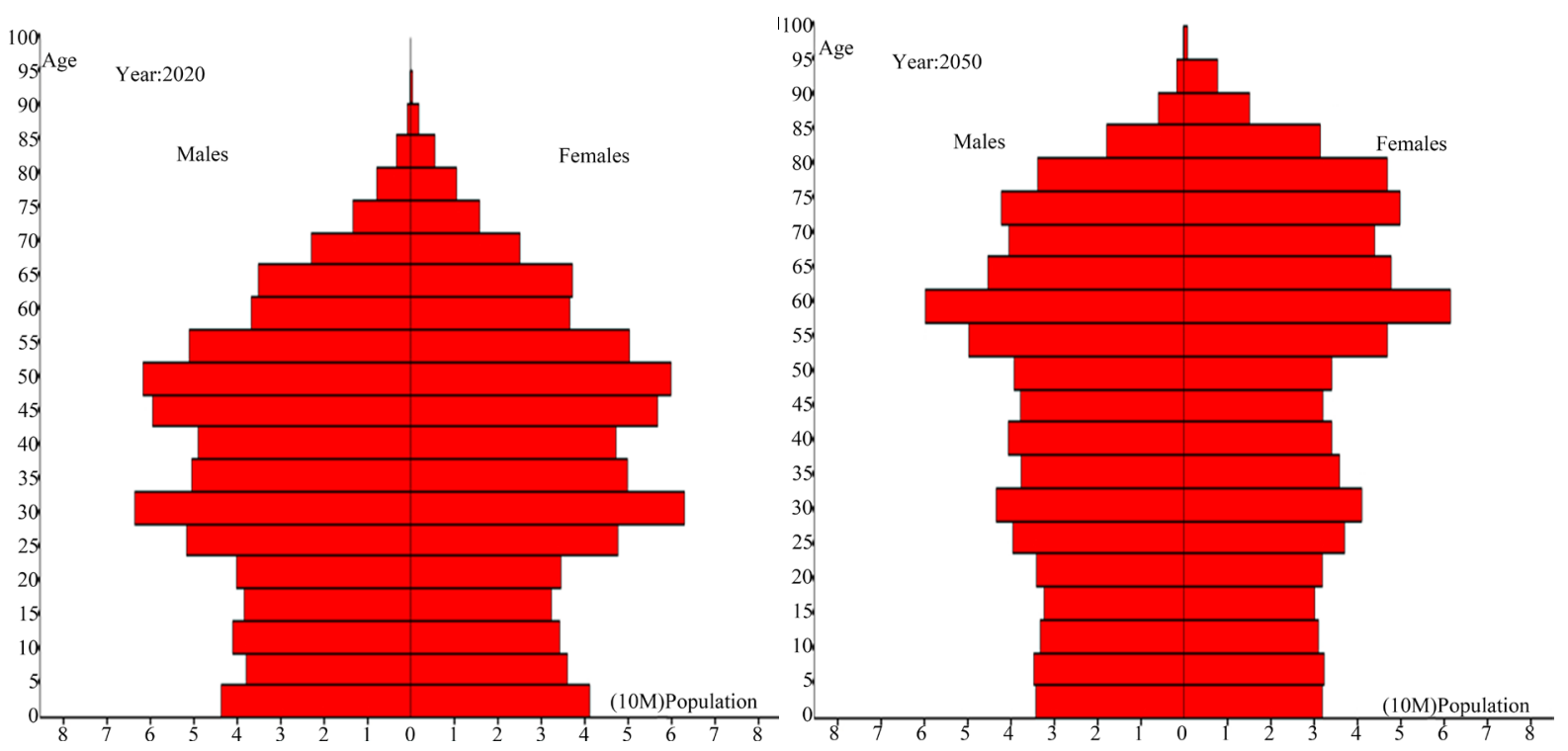

Figure 6. Middle program: demographic pyramid in 2020, 2050.

\subsection{Unbalanced Sex Ratio Analysis}

According to media reports: "by 2020, the number of men of marriageable age than women in China more than the 30 million to 40 million, which means that in an average of five men can not find a mate.” But after a certain observation and calculation, we find that the gender imbalance is not so serious yet to be confirmed. We do not rule out the sex ratio is high, but the data is not to be "too high" estimates or data itself has a problem, according to the method of longitudinal studies on past data inference can explanation some problems.

Methodologically speaking, simply look at the sex ratio, can not determine the early 1980s population concealed omissions on sex, especially in the case we want to find out whether the baby boy is also reporting, and we can not analyze units remain on the sex ratio synthesis unit, only through sex-disaggregated data can we prove such omissions of baby boy and baby girl [4]. So we have to look for concealed and unreported data by comparison with data by age and gender, as shown in Table 10 and Table 11. 

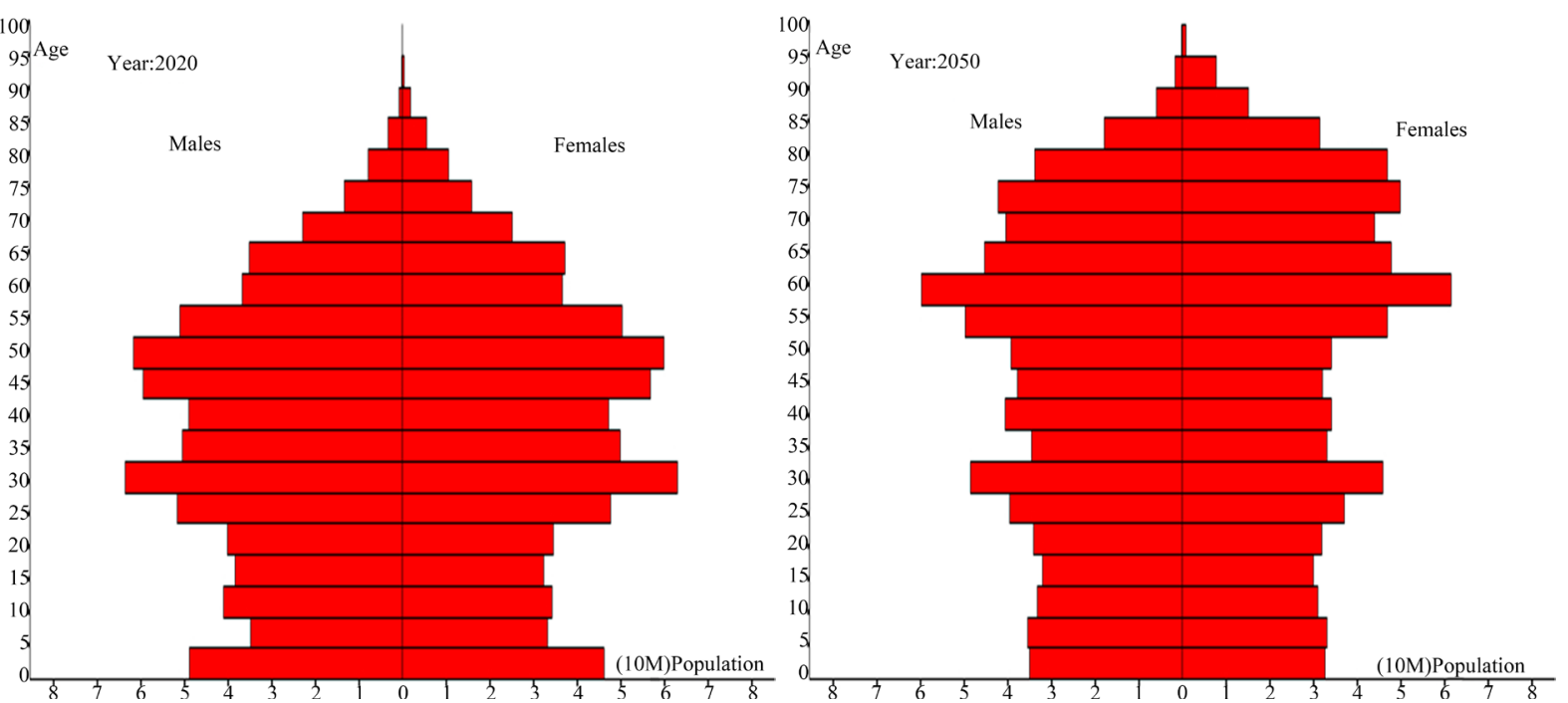

Figure 7. High program: demographic pyramid in 2020, 2050.

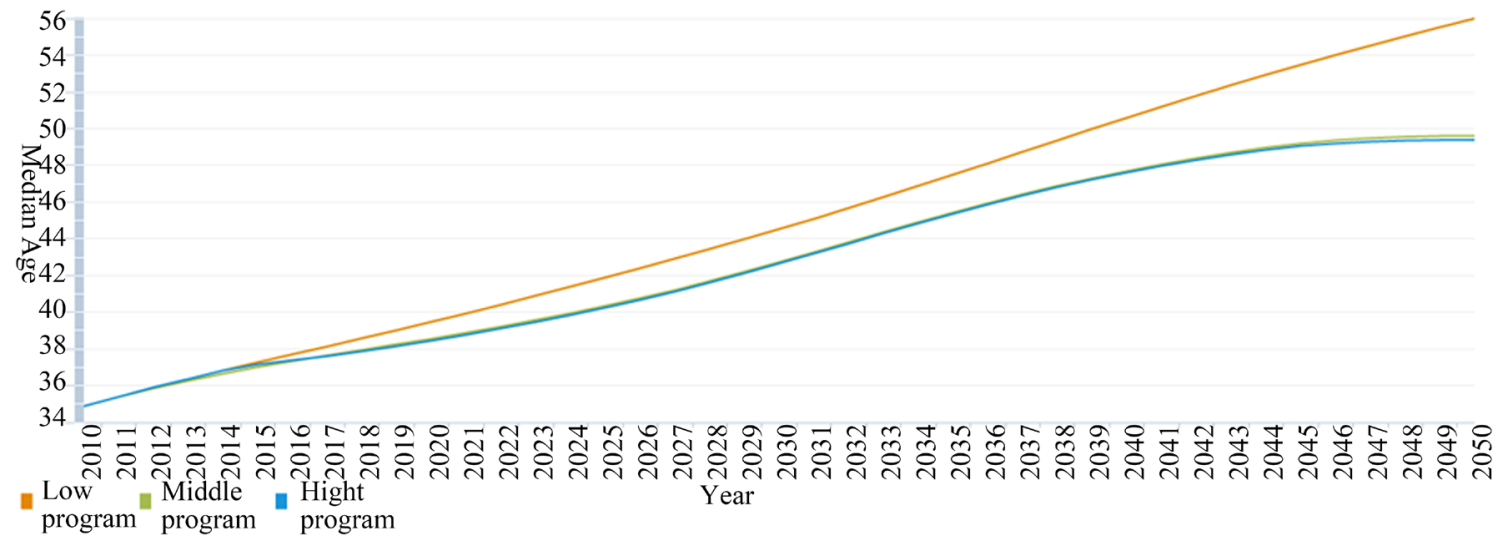

Figure 8. The median age trend.

From the above two figures (Figure 9 and Figure 10) (Black lines represent the number of males or females aged 0 - 9 years in 2000; Red lines represent the number of males or females aged 10 - 19 years in 2010) it can be found that the data graph drawn based on the fifth and sixth Census has problems. Because, according to population development process, consider the incident caused by illness and accident, in 2010 the population aged 10 - 19 should be less than or data lines coincide in the age of the data line aged 0 - 9 in 2000, so figure shows changes in male and female demographic data among all age groups in violation of the law. We can be sure that in 2000 the population in each age group of 0 - 9 years there is a big omission has concealed.

We get Table 4, Table 5 by subtracting, the number of males or females aged 10 - 19 years in 2010 subtract the number of males or females aged 0 - 9 years in 2000. If based on 2010 census data, 0 age group of the population in 2000 after 10 years, in 2010 census data in the corresponding group of men increased 934,493 people, females increased 875,342 people, indicating born in 2000 population underreporting the number of concealed boys more than the girls nearly 59151 people; In 2000, 1 age group of the population after 10 years, increased 505,504 men, women increased 677,232 people, indicating that the number of unreported concealed girls born in 1999 more than the boys 171,728 people; The number change of 2-year-old population in 2000 shows, in 20002010 years baby boy repay population higher than baby girl, 187,980 people, and so on. In 2000, the total number of female population is larger than the total number of male population repay repay, that in 2000 the population group aged 0 - 4 years baby boy omission indeed slightly higher than the number of false negatives. Therefore, sex ratio in 2000 may be lower than shown in the census.

In addition, according to the front part of analysis of the result of the total population projections and popula- 
Table 10. 2000 census data, the population group aged 0 - 4 years changes in circumstances.

\begin{tabular}{|c|c|c|c|c|c|}
\hline 2000 & & & 2010 & & \\
\hline Age & Male & Female & Age & Male & Female \\
\hline 0 & 6896316 & 5748208 & 10 & 7830808 & 6623549 \\
\hline 1 & 7017055 & 5735925 & 11 & 7522558 & 6413156 \\
\hline 2 & 7799459 & 6433064 & 12 & 8288987 & 7110572 \\
\hline 3 & 8077190 & 6762119 & 13 & 8161000 & 7064032 \\
\hline 4 & 8707371 & 7371550 & 14 & 8463924 & 7429876 \\
\hline 5 & 9011804 & 7690045 & 15 & 9524898 & 8499586 \\
\hline 6 & 9228213 & 7964235 & 16 & 9795181 & 8995340 \\
\hline 7 & 9802318 & 8531113 & 17 & 10760828 & 10014541 \\
\hline 8 & 10344592 & 9072474 & 18 & 10744556 & 10010718 \\
\hline 9 & 12242996 & 10903038 & 19 & 11079367 & 10464099 \\
\hline
\end{tabular}

Table 11. Data difference in each age group of the population.

\begin{tabular}{cc|}
\hline \multicolumn{3}{c}{ Sixth census-fifth census } \\
\hline Male & Female \\
\hline 934493 & 875342 \\
505504 & 677232 \\
489528 & 677508 \\
83811 & 301913 \\
-243447 & 58327 \\
513094 & 809541 \\
566968 & 1031105 \\
958510 & 1483428 \\
399964 & 938244 \\
-1163629 & -438939 \\
\hline
\end{tabular}

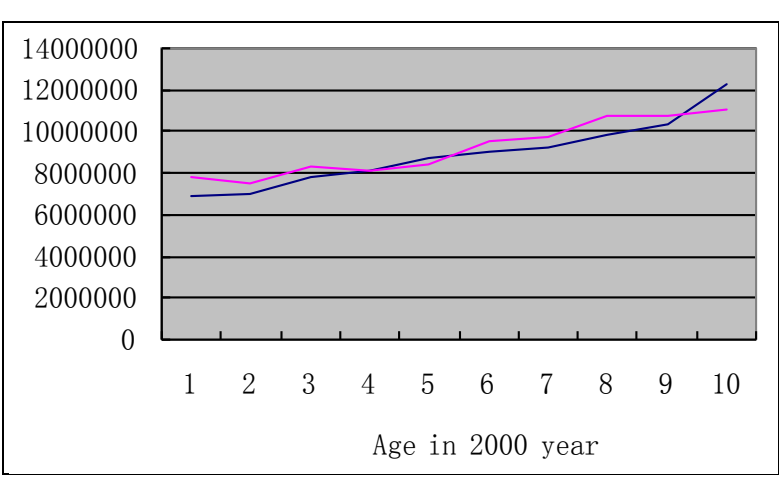

Figure 9. 0 - 9-year-old males in each age group five or six times in reference to Figure Census. 


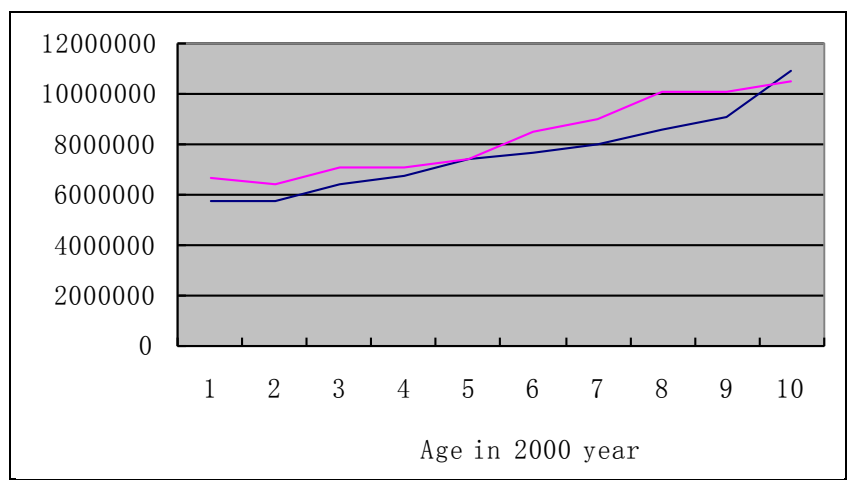

Figure 10. 0 - 9-year-old females in each age group five or six times in reference to Figure Census.

Table 12. Age-specific fact sheet.

\begin{tabular}{|c|c|c|c|c|c|c|c|}
\hline Age & Male & Female & Total people & Age & Male & Female & Total people \\
\hline $\mathbf{0}$ & 8850388 & 8349051 & 17199439 & 51 & 12576661 & 12200152 & 24776813 \\
\hline 1 & 9324522 & 8811004 & 18135526 & 52 & 12665605 & 12325269 & 24990874 \\
\hline 2 & 9788586 & 9262867 & 19051453 & 53 & 12202176 & 11902945 & 24105121 \\
\hline 3 & 10225814 & 9691347 & 19917161 & 54 & 11751536 & 11493425 & 23244961 \\
\hline 4 & 10612667 & 10073490 & 20686158 & 55 & 11155347 & 10955241 & 22110588 \\
\hline 5 & 8648059 & 8221818 & 16869877 & 56 & 10730650 & 10574247 & 21304897 \\
\hline 6 & 6585986 & 6271720 & 12857706 & 57 & 10315195 & 10204306 & 20519501 \\
\hline 7 & 6592292 & 6288097 & 12880389 & 58 & 9676014 & 9583928 & 19259943 \\
\hline 8 & 6552045 & 6260049 & 12812093 & 59 & 9070194 & 8999224 & 18069419 \\
\hline 9 & 6470591 & 6192496 & 12663088 & 60 & 8083749 & 7983175 & 16066924 \\
\hline 10 & 8381995 & 7032351 & 15414347 & 61 & 7565850 & 7490602 & 15056452 \\
\hline 11 & 8291975 & 6958954 & 15250929 & 62 & 7075324 & 7025418 & 14100743 \\
\hline 12 & 8188636 & 6878416 & 15067052 & 63 & 7026323 & 7059160 & 14085483 \\
\hline 13 & 8082942 & 6795743 & 14878685 & 64 & 6971893 & 7089948 & 14061841 \\
\hline 14 & 7977287 & 6713010 & 14690297 & 65 & 7461601 & 7762081 & 15223682 \\
\hline 15 & 7769882 & 6530935 & 14300818 & 66 & 7383542 & 7781520 & 15165063 \\
\hline 16 & 7668673 & 6451333 & 14120006 & 67 & 7295013 & 7792422 & 15087434 \\
\hline 17 & 7568035 & 6372388 & 13940423 & 68 & 6726426 & 7224210 & 13950636 \\
\hline 18 & 7635897 & 6457033 & 14092930 & 69 & 6192618 & 6689786 & 12882404 \\
\hline 19 & 7703589 & 6542477 & 14246066 & 70 & 5472747 & 5900088 & 11372835 \\
\hline 20 & 7673915 & 6513767 & 14187682 & 71 & 5013912 & 5445129 & 10459042 \\
\hline 21 & 7741264 & 6599555 & 14340819 & 72 & 4581011 & 5015664 & 9596675 \\
\hline 22 & 7808982 & 6686299 & 14495281 & 73 & 4137975 & 4597548 & 8735523 \\
\hline 23 & 8211778 & 7134810 & 15346588 & 74 & 3727526 & 4205962 & 7933488 \\
\hline 24 & 8635042 & 7613179 & 16248221 & 75 & 3281356 & 3772213 & 7053569 \\
\hline
\end{tabular}




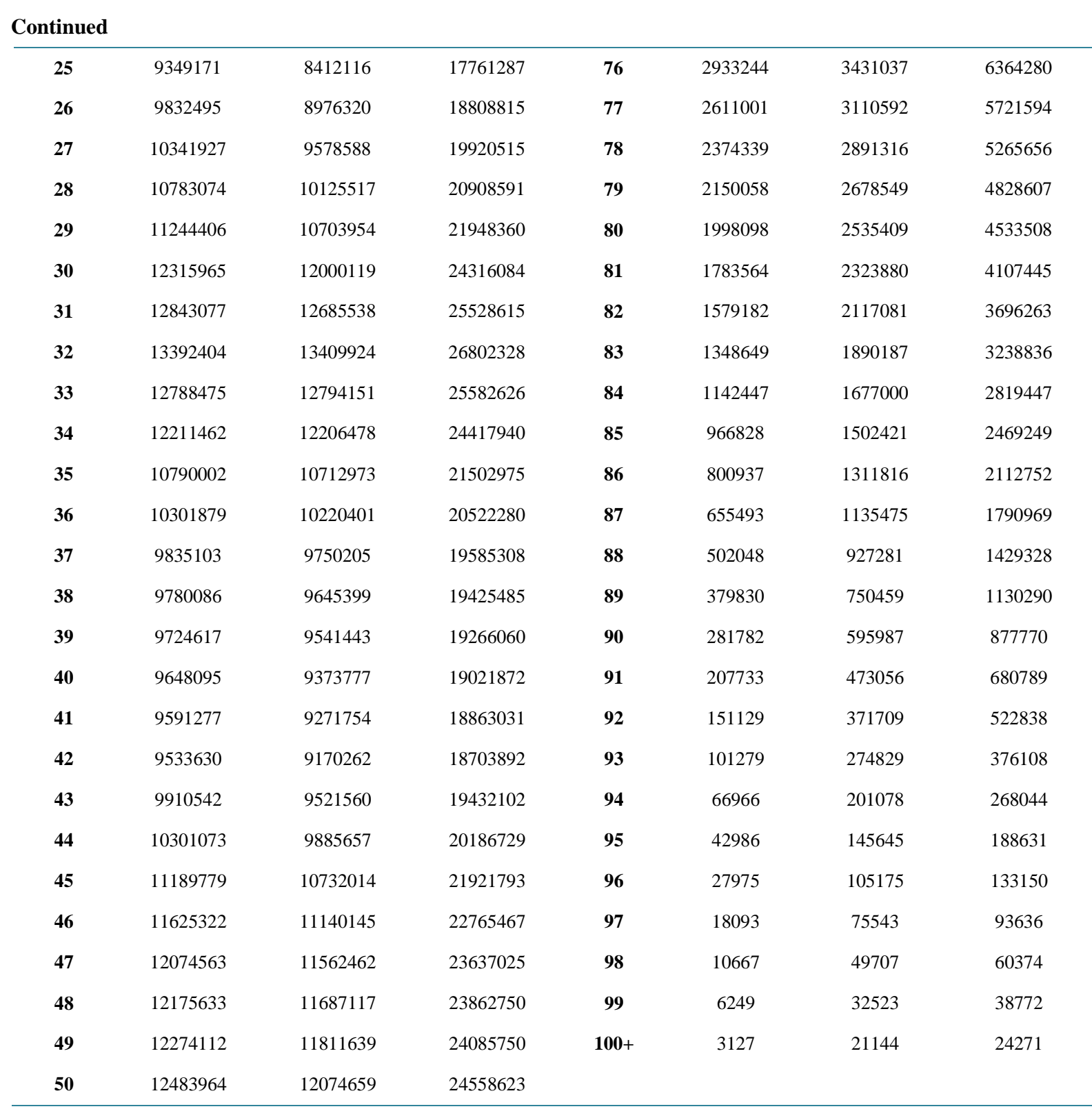

tion structure between 2015-2050, we can know the cases of age and gender in 2020, as shown in Table 12.

The above table shows that in 2020 marriageable age [20,34], the total male population is 145,512,986, the total female population is $133,439,196$, more men than women 12073790 , bachelor amount reported a gap, but it coincided with the argument that women underreporting rate higher than men.

So, to sum up, by 2020, the number of men will more than the number of women, bachelor phenomenon will occur, however, the amount does not reach the bachelor as high as reported in reports.

\section{Conclusion and Suggestion}

Based on the data of the sixth census, the article predicts the trend of population structure change in China from 2015 to 2050. Since the fourth part of the article we demonstrate that the existence of Chinese male and female fertility exists underreporting phenomenon, but when we do the total population and population structure analysis are not added to the false negative rate, which are the biggest shortcomings of this article. Therefore, to improve, we can start from the false negative rate. However, due to limited space, there is no longer recalculated. 
By comparing the change in the trend of population structure under three different fertility programs, we believe that:

1) To maintain current family planning policy unchanged will make China a serious aging population structure, which is imperative to adjust the family planning policy.

2) Moderate fertility program, the implementation of the two-child family planning policy can significantly improve the structure of China's population aging problem, but will not bring too many new people. It is an ideal choice for our future family planning policy.

3) Sex-ratio imbalance is mainly due to the preference of fertility concept to men, fetal gender identification in non medical needs, flaws in the relevant laws and regulations, ineffective medical supervision and other factors. Therefore, we need consider these factors synthetically to further strengthen the governance of sex ratio at birth.

\section{References}

[1] Li, X.Y., Xi, Y.Y. and Wu, X.M. (2014) Two Children Alone Policy of Population Affected by Natural Changes to Predict. Economic Management Research, 5, 47-53.

[2] Alho, J.M. (1998) A Stochastic Forecast of the Population of Finland, Review. Statistics Finland, Helsinki.

[3] Keyfitz (1996) Population Growth, Development and Environment. Population Studies, 50, 335-359. http://dx.doi.org/10.1080/0032472031000149526

[4] Liu, C.B. and Feng, X.T. (2008) China Population Sex Ratio: We Know What, You Should Also Know What. Population and Development, 2, 36-46.

\section{Submit or recommend next manuscript to SCIRP and we will provide best service for you:}

Accepting pre-submission inquiries through Email, Facebook, Linkedin, Twitter, etc

A wide selection of journals (inclusive of 9 subjects, more than 200 journals)

Providing a 24-hour high-quality service

User-friendly online submission system

Fair and swift peer-review system

Efficient typesetting and proofreading procedure

Display of the result of downloads and visits, as well as the number of cited articles

Maximum dissemination of your research work

Submit your manuscript at: http://papersubmission.scirp.org/ 